\title{
Case: Anuria and acute renal failure post-endoscopic valve ablation and Foley catheter insertion in a newborn with a small-capacity, non-compliant bladder
}

\author{
Adriana Dekirmendjian, BHSc'; Melissa McGrath'; Luis H. Braga, MD, MSc, PhD ${ }^{1,2}$ \\ 'McMaster Pediatric Surgery Research Collaborative, Department of Surgery; 2Division of Urology, Department of Surgery; McMaster University, Hamilton, ON, Canada
}

Cite as: Can Urol Assoc J 2017;11 (9):E382-4. http://dx.doi.org/10.5489/cuaj.4466

Published online September 12, 2017

\section{Introduction}

Bladder wall thickening, decreased bladder capacity, and compliance may present unforeseen challenges when performing primary valve ablation. ${ }^{1}$ Herein, we describe the unique case of a neonate with posterior urethral valves (PUV), bilateral hydroureteronephrosis, and a very small, non-compliant (stiff) bladder, who developed anuria and acute renal failure immediately following endoscopic valve ablation and Foley catheter insertion.

\section{Case report}

A male neonate had a postnatal ultrasound (US) on Day 2 of life that revealed bilateral Society for Fetal Urology (SFU) Grade IV hydronephrosis with dilated tortuous ureters in their entirety (maximum diameter $=11 \mathrm{~mm}$ ), and considerable bladder wall thickening. Diagnosis of PUV was confirmed by voiding cystourethrogram (VCUG), which demonstrated bladder wall trabeculation, small bladder capacity, bilateral Grade $V$ vesicoureteral reflux (VUR), as well as dilatation of the prostatic urethra (Fig. 1).

Endoscopic valve ablation and circumcision were performed on Day 4 of life, with insertion of an 8 French Foley catheter inflated to $1.0 \mathrm{ml}$. Shortly after the procedure, decreased urinary output was observed and voiding was noted from around the catheter. The catheter was checked and was flushing well, thus ruling out obstruction or kink. The neonate also displayed a marked increase in serum creatinine, rising from $75 \mu \mathrm{mol} / /$ preoperatively to $139 \mu \mathrm{mol} / \mathrm{I}$ overnight. On postoperative Day 4, creatinine continued to rise, reaching $332 \mu \mathrm{mol} / \mathrm{l}$, as urinary output decreased, falling to only $0.5 \mathrm{ml} / \mathrm{kg} / \mathrm{hr}$, with a small amount of urine draining from the catheter. Repeat US demonstrated persistent severe bilateral hydroureteronephrosis, as well as a thickwalled, empty bladder with a Foley catheter in place (Fig. 2). Due to progressive development of oliguria, leading to anuria and subsequent acute renal failure, insertion of a peritoneal dialysis (PD) catheter was indicated. Intraoperative examination revealed a small, hard bladder (golf-ball consistency) palpable above the pubic bone. Immediately following deflation of the Foley catheter balloon from $1.0 \mathrm{ml}$ to $0.5 \mathrm{ml}$, urine output was noted, reaching $75 \mathrm{~mL}$ by the end of the PD insertion. A rapid decrease in creatinine was observed, falling from $332 \mu \mathrm{mol} / \mathrm{l}$ at the time of surgical intervention, to $64 \mu \mathrm{mol} / /$ within two days (Fig. 3).

\section{Discussion}

Although mortality rates have significantly declined, PUV continues to exert deleterious effects on bladder and renal functions, as seen by the high rate $(50 \%)$ of end-stage renal disease in these children. ${ }^{1,2}$ As a result, time-sensitive detection and management of PUV is necessary to preserve renal function and ameliorate long-term complications. ${ }^{3}$

Due to the obstructive nature of PUV, development of detrusor hypertrophy, low bladder compliance, and high pressure are some of the subsequent changes that take place in the urinary bladder. ${ }^{1,4}$ Such changes in the detrusor muscle must be considered in the context of any future surgical intervention, as they can greatly impact placement and drainage of urinary catheters. Casale forewarns that the use of a Foley catheter may cause irritation and subsequent bladder spasms in children with PUV. ${ }^{3}$ Severe spasms, in addition to a thick-walled bladder with low compliance, may obstruct the flow of urine into the bladder. As a result, it is recommended that catheter placement be confirmed either by catheter irrigation or bladder imaging.

According to our literature search, only three documented cases of obstructive anuria following placement of a Foley catheter in infants with PUV have been previously described.$^{5-7}$ Similar to our case, renal failure and anuria were 


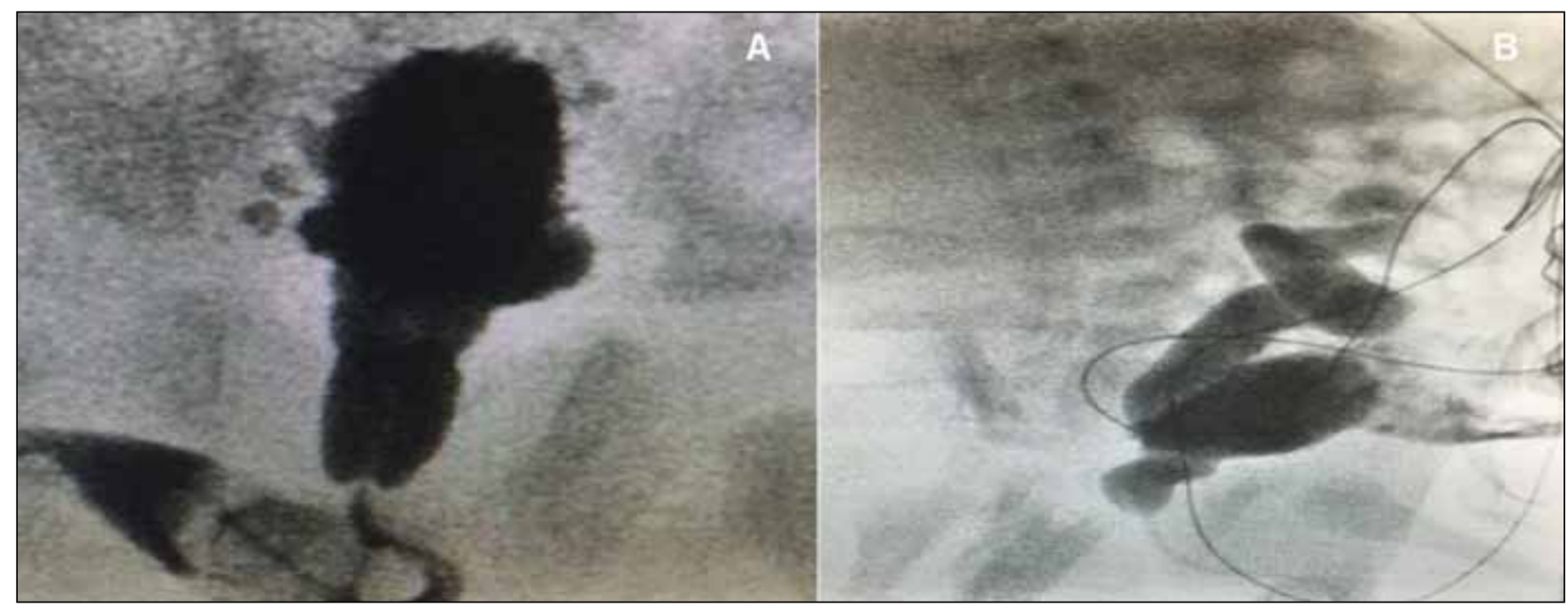

Fig 1. Voiding cystourethrogram. (A) Preoperative voiding cystourethrogram demonstrating a small, trabeculated bladder with dilation of the posterior uerethra; $(\boldsymbol{B})$ voiding cystourethrogram indicative of vesicoureteral reflux.

observed post-valve ablation and Foley catheterization, with significant improvements in renal function observed after deflation of the Foley catheter balloon. The hypertrophied, low-capacity, poor-compliant bladder that is occasionally seen in young infants with PUV can be severely compromised by the insertion of a Foley catheter, even with small amounts of water injected in the balloon, causing worsening of pre-existent hydroureteronephrosis and development of acute renal failure, as seen in our case. Clinicians must be familiar with this potential risk and any doubts regarding Foley catheter balloon position should be confirmed by US.

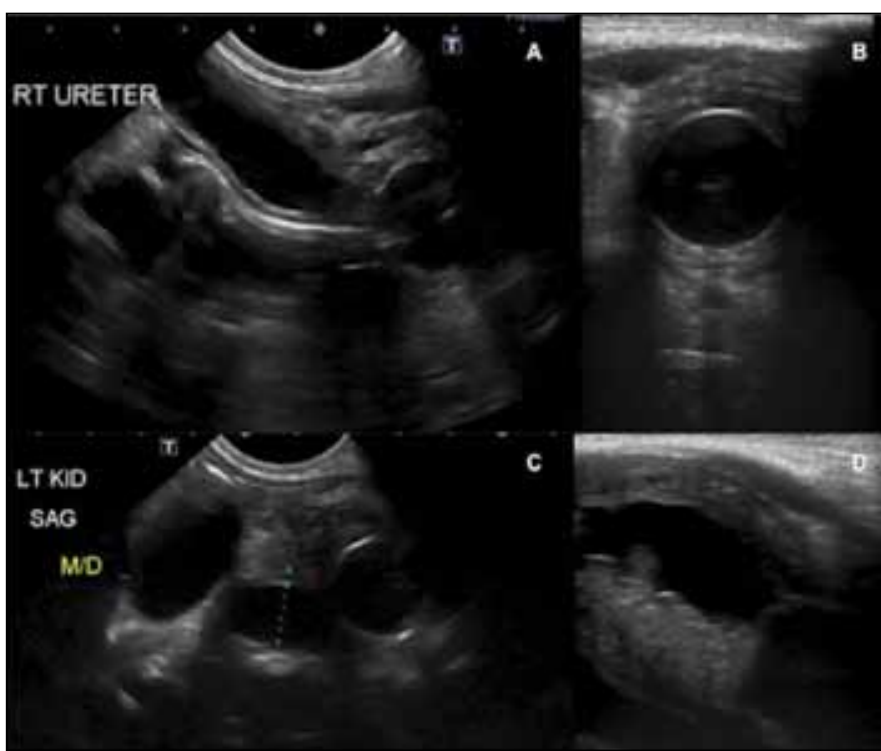

Fig. 2. Postoperative ultrasound following valve ablation. (A) Dilated right ureter; $(\boldsymbol{B})$ small-capacity, thick-walled empty bladder occupied in its entirety by Foley catheter; $(\boldsymbol{C})$ dilated left ureter and Foley catheter visualized on sagittal image; and (D) substantial bladder wall thickening demonstrated on sagittal image.
In addition, these balloons must be inflated to a minimum volume (usually less than $1 \mathrm{ml}$ ) to avoid blocking the ureteral orifice in children with PUV.

Alternative options for lower urinary tract decompression, such as placement of a double J ureteric stent, can also be considered in children with PUV to decrease bladder spasms, potentially reducing the deleterious effect of a spastic and over-reactive bladder. ${ }^{8}$

\section{Conclusion}

Although a rare event, inflation of even a Foley balloon, among other factors, may be associated with untoward consequences in the newborn with PUV, especially in the face of a spastic, small-capacity bladder.

Competing interests: The authors report no competing personal or financial interests.

This paper has been peer-reviewed.

\section{References}

1. Lopez Pereira $P$, Martinez Urrutia M, Jaureguizar E. Initial and long-term management of posterior urethral valves. World J Urol 2004;22:418-24. https://doi.org/10.1007/s00345-004-0460-6

2. Taskinen $S$, Heikkilä J, Rintala R. Posterior urethral valves: Primary voiding pressures and kidney function in infants. J Urol 2009;182:699-703. https://doi.org/10.1016/i.juro.2009.04.035

3. Casale AJ. Posterior urethral valves. In: Wein AJ, editor. Campbell-Walsh Urology. 10th ed. Philadelphia: Elsevier; 2012:3389-3410. https://doi.org/10.1016/B978-1-4160-6911-9.00126-2

4. Thomas J. Etiopathogenesis and management of bladder dysfunction in patients with posterior urethral valves. Indian J Urol 2010;26:480-9. htrps://doi.org/10.4103/0970-1591.74434

5. Sarkis $P$, Robert $M$, Lopez $C$, et al. Obstructive anuria following fulguration of posterior urethral valves and Foley catheter drainage of the bladder. Br J Urol 1995;76:664-5. https://doi.org/10.1111/i.1464410X.1995.tb07804.x 
Dekirmendjian et al

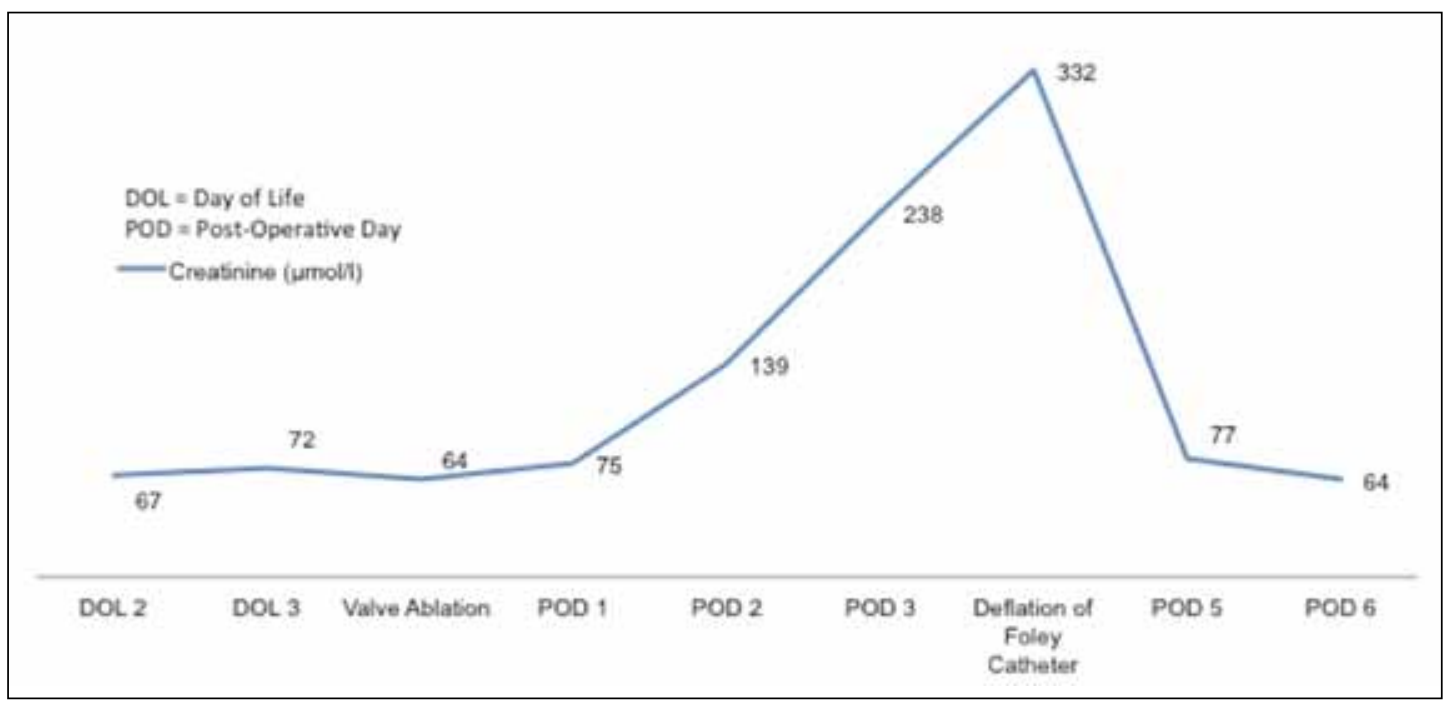

Fig. 3. Creatinine vs. time graph.

6. Noe HN, Jerkins GR. Oliguria and renal failure following decompression of the bladder in children with posterior urethral valves. J Urol 1983;129:595-7. https://doi.org/10.1016/S0022-5347(17)52252-1

7. Jordan GH, Hoover DL. Inadequate decompression of the upper tracts using a Foley catheter in the valve bladder. J Urol 1985;134:137-8. https://doi.org/10.1016/S0022-5347(17)47027-3

8. Penna FJ, Bowlin P, Alyami F, et al. Novel strategy for temporary decompression of the lower urinary tract in neonates using a ureteral stent. J Urol 2015;194:1086-90. https://doi.org/10.1016/i. juro.2015.04.102
Correspondence: Dr. Luis H. Braga, Department of Surgery/Urology, McMaster University, Hamilton, ON, Canada; braga@memaster.ca 